\title{
Using recycled water for agricultural purposes in the Thessaly region, Greece: a primary investigation of citizens' opinions
}

\author{
S. Bakopoulou, I. Katsavou, S. Polyzos \& A. Kungolos \\ Department of Planning and Regional Development, \\ University of Thessaly, Greece
}

\begin{abstract}
The purpose of this study was to investigate citizens' opinions regarding wastewater reuse applications (especially irrigation applications) in Thessaly region, Greece. Thessaly region is located in central eastern part of Greece and its main feature is that a relatively high percentage of its population is partly or fully employed in agriculture. Furthermore, Thessaly region suffers from a distinct water shortage in summer period, which is partly attributed to the increased agricultural activity. Thus, it is believed that recycled water use for agricultural irrigation activities could be a satisfactory solution to the problem. Our purpose was to see if Thessaly citizens would be willing to accept recycled water being incorporated in water management plans of their area. The method followed for the above investigation was contingent valuation one which aims at evaluating nonmarket environmental resources through personal interviewing. Our study was based on data collected from 200 questionnaires, which were answered by citizens - consumers in Thessaly region. The group chosen for our study was random and the questionnaires were answered through personal interviewing. The data collected were then statistically analyzed. The main results show that Thessaly citizens are willing to use agricultural products irrigated with recycled water if they have sufficient information regarding wastewater reuse practices in Greece. Keywords: recycled water use, citizens' acceptability, Thessaly region.
\end{abstract}

\section{Introduction}

Water scarcity and deterioration in the quality of water resources observed in many countries recently have led to the recognition that a careful water resource 
management should be adopted. This management should incorporate alternative water resources use among others. Desalination of seawater, as well as reclamation and reuse of municipal wastewater constitute the main strategies that have been proposed for investigation and application in many countries all over the world.

Recycling of water is becoming an important management practice in recent years. This is because treated wastewater from urban areas is a recognised water resource that can be used for a number of purposes, especially in areas afflicted by water shortage. The most common use is for non-potable purposes such as agricultural and urban irrigation uses. Other uses such as industrial ones (cooling, etc), environmental enhancement (wetlands, wildlife refuges, riparian habitats, etc), fire fighting, dust control, and toilet flushing have also been developed in many countries. All these uses require treatment of the effluent so that it meets the quality requirements for the intended use. Adequate infrastructure such as storage reservoirs, and canals, pipelines and dual distribution systems are also necessary so that waters of different qualities can be transported to different destinations. Aesthetics and public acceptance are important aspects of water reuse, especially where the public is directly affected [1].

In Greece, water demand has increased over the past 50 years. Water imbalance is often experienced, due to temporal and regional variations of the precipitation, the increased water demand during the summer months and the difficulty of transporting water due to the mountainous terrain. In addition, in many eastern areas there is severe pressure for freshwater resources, which is exacerbated by especially high demand of water for tourism and irrigation. Today, almost $60 \%$ of the Greek population is connected to over 300 centralised wastewater treatment plants with a total capacity of over $1,30 \mathrm{Mm}^{3} / \mathrm{d}$. An analysis of data concerning the water balance of the areas of the treatment plants demonstrated that more than $83 \%$ of the treated effluents are produced in regions with a deficient water balance. Therefore, water reuse in these areas would satisfy an existing water demand [2].

Thessaly region is included in regions which suffer from a deficient water balance, especially in summer months, because of increased agricultural activity. The aim of our study is to determine whether Thessaly citizens are eager to accept water reuse being incorporated in water management plans of their area. In Thessaly region is referred a study which aimed to determine whether farmers are willing to pay to buy recycled water for their crops irrigation [3], but no relative study has taken in mind the whole of citizens in the region.

\section{Case study area}

Thessaly region is located in central eastern part of Greece and includes prefectures of Larissa, Magnesia, Trikala and Karditsa (Figure 1). The population of the region in 2001 reached up to 754393 inhabitants within an area of $14037 \mathrm{~km}^{2}\left(53,7\right.$ inhabitants $\left./ \mathrm{km}^{2}\right)$.

The main feature of Thessaly region is that a relatively high percentage of its population is partly or fully employed in agriculture. Thus, an increased 


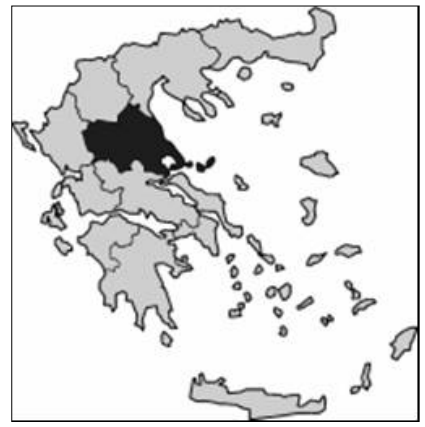

Figure 1: $\quad$ Location of Thessaly region in Greece.

agricultural activity is observed in the region. Furthermore, Thessaly region suffers from significant water shortage during summer period. This shortage is partly attributed to the relatively high temperatures observed in the region in summer months, but is mainly attributed to the increased agricultural activity. Total irrigated area in the region reaches up to 240000 ha. This area is now partly irrigated with approximately $750 \mathrm{Mm}^{3}$ of water, while full irrigation of the area demands approximately $1600 \mathrm{Mm}^{3}$ of water. The utilization of water from a different water region (Western Greece water region, Achelloos river) constitutes the main policy that is currently examined as a valid solution of the problem. However, water shortage may still exist even after water of Achelloos river will have been used in Thessaly region [4]. Thus, alternative water resources use should be incorporated in region's water management plans.

\section{Methodology}

\subsection{Contingent valuation method}

The objective of this study is to investigate Thessaly citizens' knowledge of water recycling, their willingness to accept recycled water being incorporated in region's water management plans as well as their willingness to pay for such water resource. The method used for the above investigation is contingent valuation method (CVM) which belongs to stated preference methods. Stated preference methods (SPM) have been developed to solve the problem of valuing those environmental resources that are not traded in real markets. The purpose of the contingent valuation method is to elicit individuals' preferences, in monetary terms, for changes in the quantity or quality of nonmarket environmental resources. With contingent valuation method, valuation is dependent upon a hypothetical situation or scenario whereby a sample of the population is interviewed and individuals are asked to state their willingness to accept a situation or pay for an increase, or decrease, in the level of environmental quantity or quality [5].

Different contingent valuation studies have been undertaken worldwide to elicit citizens' willingness to pay for water management related projects. There are 
studies aiming at investigating residents' willingness to accept the construction of municipal and industrial wastewater treatment plants in their area and pay for them $[6,7]$. In such cases, the potential gainers "buy" cleaner water bodies for themselves, for tourism, and for fisheries. On the other hand, contingent valuation method has been used for evaluating water ecosystems restoration feasibility. Loomis et al. (2000) have investigated willingness of households to accept an increase in their water bill to ensure the restoration of a nearby river ecosystem [8]. Karkanakis et al. (2005) have estimated the willingness of visitors to Cournas lake, Greece to pay for the facilities and provided services in the lake as well as for the protection of the lake itself [9]. Contingent valuation method has also been used for pricing of irrigating water [10] and investigating farmers' willingness to use recycled water and pay for it $[3,11,12,13]$. Surveys aiming at investigating consumers' willingness to buy agricultural products irrigated with recycled water have also used contingent valuation method [12].

\subsection{Survey structure}

This study was based on data collected from 200 questionnaires, which were answered by citizens from various parts of Thessaly region. The method followed for questionnaires answering was that of personal interview while the sample chosen was random.

Each questionnaire was divided in two different sections. The first section (questions 1-5, Table 1) dealt with personal data of interviewees while the second one (questions 6-9, Table 1) had as a purpose to inform them for the advantages and disadvantages of wastewater reuse and see if they are willing to use agricultural products irrigated with recycled water and pay for such products.

The questions included in the questionnaire presented in Table 1.

It should be noticed that in second session we started with interviewees' informing about terms like "municipal wastewater", "wastewater treatment" and "wastewater recycling". Regarding "municipal wastewater" and "wastewater treatment", it was explained to interviewees what municipal wastewater contains and how this kind of water may be purified in order to be reused. Regarding "wastewater recycling", we analyzed to the respondents the potential risks and benefits arising when someone uses such water resources. Special emphasis was given to potential pollution risks arising when wastewater is not handled properly. Finally, some examples of wastewater reuse projects in other countries were presented to the respondents.

\section{Results and discussion}

The data collected from our questionnaires were then statistically analyzed by use of SPSS statistical package. Results show that the majority of consumers that participated in our survey were female with an average age of about 40 years. The $63 \%$ of respondents have had a university degree while an only $12 \%$ have received a primary education. The average monthly income of our respondents sample reaches up to approximately 1100 Euros. These results are depicted in Figures 2 and 3. 
Table 1: Questionnaire structure.

\begin{tabular}{|c|c|}
\hline Question & Options offered \\
\hline 1. Sex & $\begin{array}{ll}- & \text { Male } \\
\text { - } & \text { Female } \\
\end{array}$ \\
\hline 2. Age & - $\quad$ An open question \\
\hline 3. Education level & $\begin{array}{ll}\text { - } & \text { Primary school } \\
\text { - } & \text { Secondary/high school } \\
\text { - } & \text { University } \\
\end{array}$ \\
\hline 4. Income & - An open question \\
\hline $\begin{array}{l}\text { 5. Do you participate in activities } \\
\text { regarding protection of the environment? }\end{array}$ & $\begin{array}{ll}\text { - } & \text { Yes } \\
\text { - } & \text { No } \\
\end{array}$ \\
\hline $\begin{array}{l}\text { W. What have you known till now } \\
\text { regarding wastewater treatment and } \\
\text { reuse? }\end{array}$ & $\begin{array}{ll} & \text { Nothing } \\
\text { - } & \text { Enough } \\
\text { - } & \text { Fully informed } \\
\end{array}$ \\
\hline $\begin{array}{l}\text { 7. If you had available agricultural } \\
\text { products irrigated with recycled water, } \\
\text { would you use this kind of products? }^{1}\end{array}$ & $\begin{array}{ll}- & \text { Definitely no } \\
\text { - } & \text { Probably } \\
\text { - } & \text { Yes of course } \\
\text { - } & \text { I have no opinion } \\
\end{array}$ \\
\hline $\begin{array}{l}\text { 8. How much would you pay for } \\
\text { agricultural products irrigated with } \\
\text { recycled water in comparison with } \\
\text { present price of the product? }\end{array}$ & - $\quad$ An open question \\
\hline $\begin{array}{l}\text { 9. Would you ever visit a park irrigated } \\
\text { with recycled water, if there were } \\
\text { adequate health safety regulations? }\end{array}$ & - An open question \\
\hline
\end{tabular}

${ }^{1}$ Consumers whose answer was "no" or "probably" in this question were further asked to determine the reasons why gave this answer.

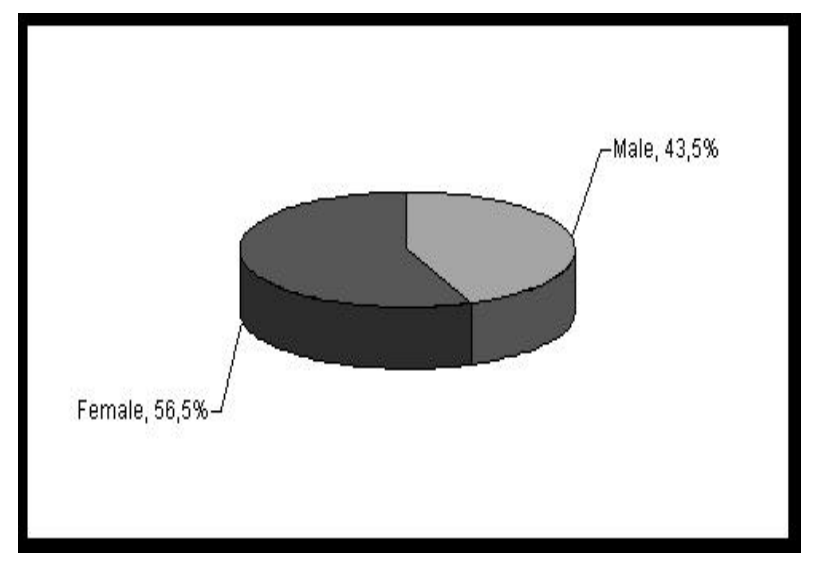

Figure 2: Distribution of Thessaly citizens according to their sex. 


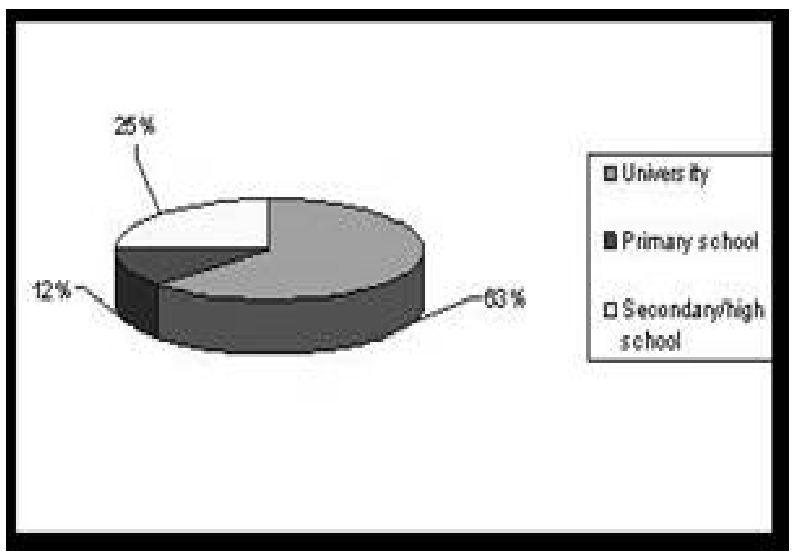

Figure 3: Distribution of Thessaly citizens according to their education level.

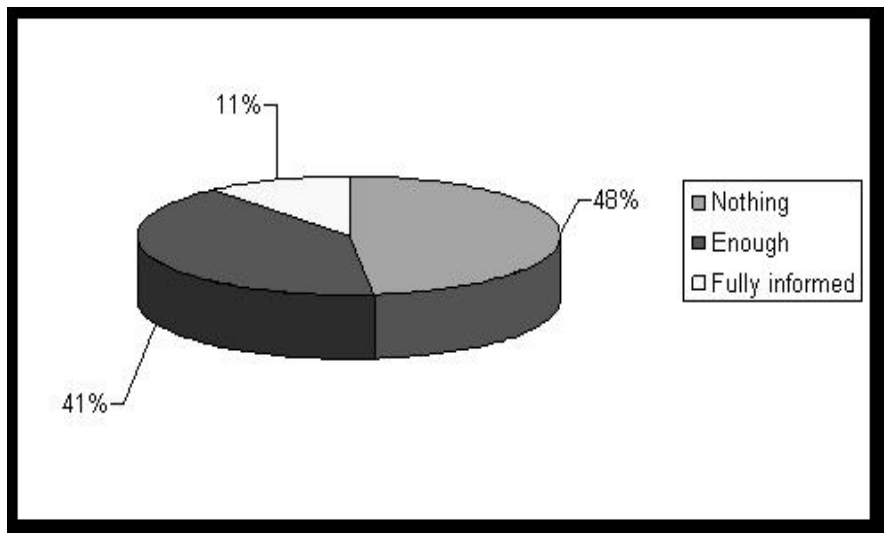

Figure 4: Distribution of answers in the question "What have you known till now regarding wastewater treatment and reuse?".

In question "Do you participate in activities regarding protection of the environment?", the $60,5 \%$ of respondents answered "no" while the remaining $39,5 \%$ said "yes". Similarly, in question regarding wastewater treatment and recycling knowledge the majority of interviewees stated that have no knowledge. However, it is encouraging the fact that consumers' willingness to use agricultural products irrigated with recycled water can be characterized rather as high (see Figure 5).

Interviewees whose answer was "definitely no" or "probably" in the previous question were further asked to say the reasons why they gave us this answer. The majority of them stated that they had no information about this kind of water resource, so they were worried about health safety issues. However, the same persons said that they did not have any problem if the corresponding agricultural products were not eatable (cotton for example). 


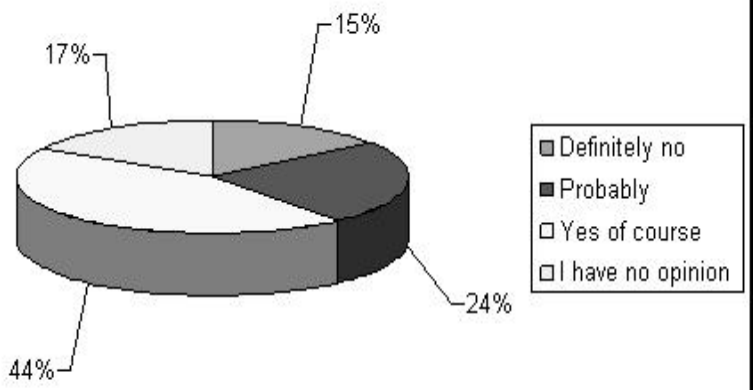

Figure 5: Distribution of answers in the question "If you had available agricultural products irrigated with recycled water, would you use this kind of products?".

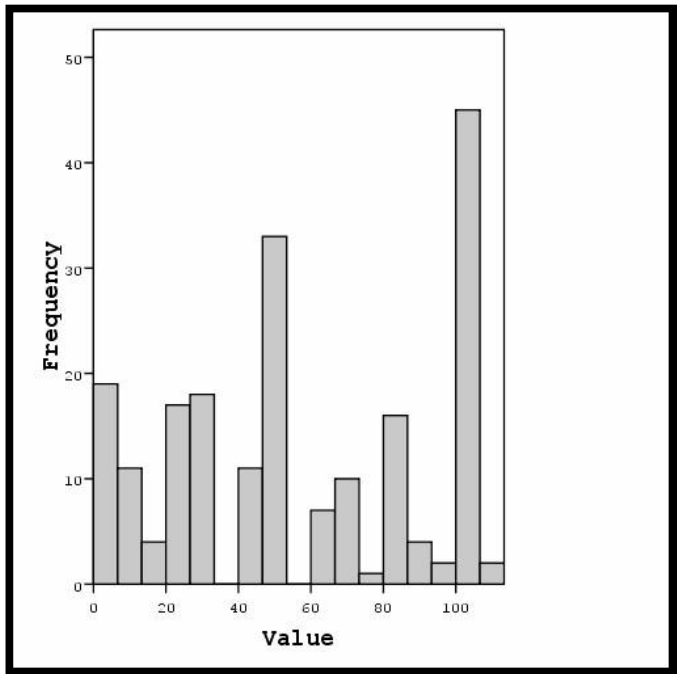

Figure 6: Distribution frequency histogram of indicated price that Thessaly consumers would be willing to pay for buying agricultural products irrigated with recycled water.

Furthermore, analysis of data collected in question 8 (see Table 1) shows that consumers are willing to pay a price in order to buy agricultural products irrigated with recycled water. The average price indicated in the questionnaires was estimated to be about the half of current product price (see Figure 6). The prices stated in our questionnaires were presented as percentages of current prices of corresponding products. 
Finally, Figure 7 shows consumers willingness to visit a park irrigated with recycled water. As it can be noticed, this willingness is very high. This is an encouraging result since recycled water use for landscape irrigation and other non - potable urban uses gain interest in recent years and should be promoted together with agricultural irrigation applications.

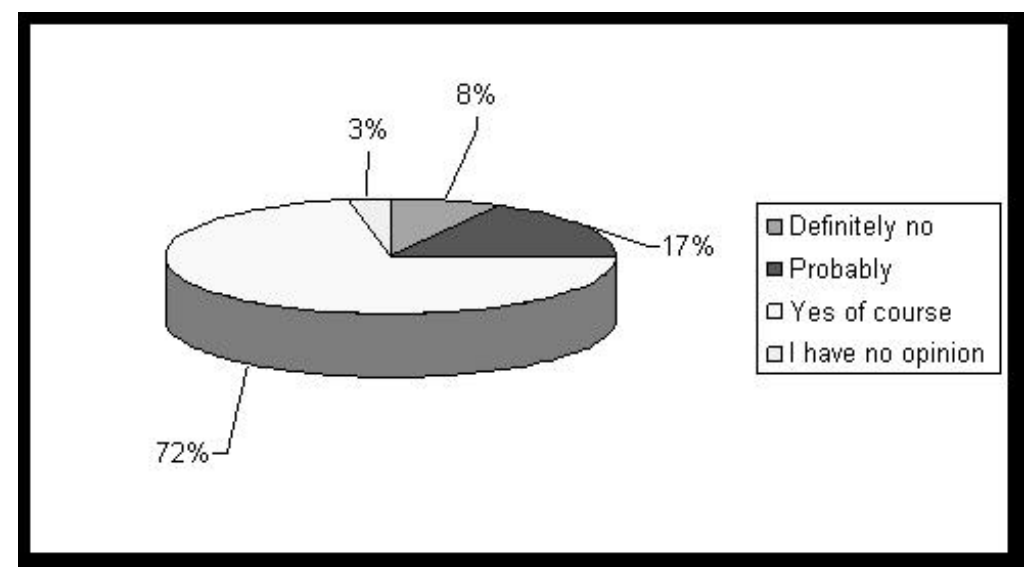

Figure 7: Distribution of answers in question "Would you ever visit a park irrigated with recycled water, if there were adequate health safety regulations?".

\section{Conclusions}

Taking in mind the above data, it can be concluded that recycled water may be used as an alternative water resource in Thessaly region since the majority of citizens in the region seem to be willing to accept recycled water being incorporated in region's water management plans. Thus, advanced treated municipal wastewater from about eight wastewater treatment plants that operate in the region may be a useful water source in cultivation areas nearby the treatment plants, especially in summer period. Information regarding wastewater treatment and reuse practices is essential in order to encourage more persons to accept the alternative water resource. The media could contribute in this effort by informing the local society for how important could be such water resource use for efficient water management and protection of the environment.

In general, an integrated system of water management in Greece and more specifically in the area of Thessaly region has to be achieved through the commitment of responsibility both by the qualified authorities at national and regional level and the local society. To achieve this, it is essential to give a priority in citizens' information about wastewater recycling benefits and risks. Only this way Greece will achieve a modern water management planning ensuring environment protection coupled with development. 


\section{Acknowledgements}

This paper is part of the 03ED375 research project, implemented within the framework of the "Reinforcement Programme of Human Research Manpower" (PENED) and co-financed by National and Community Funds (25\% from the Greek Ministry of Development-General Secretariat of Research and Technology and $75 \%$ from E.U.-European Social Fund).

\section{References}

[1] Bower, H. (2000) "Integrated water management: emerging issues and challenges". Agricultural Water Management, Vol. 45, pp 217-228.

[2] Angelakis, A.N., Bontoux, L., Lazarova, V. (2003) "Challenges and prospectives for water recycling and reuse in EU countries", Water Science and Technology: Water Supply, Vol. 3, No 4, pp 59-68.

[3] Bakopoulou, S., Polyzos, S., Kungolos, A. (2007) "Investigation of farmers' willingness to use recycled water for irrigation in Thessaly region, Greece", in proceedings of First International Conference on Environmental Management, Engineering, Planning and Economics (CEMEPE), Skiathos, Greece.

[4] Goumas, K. (2006) "Irrigation at the Thessaly basin: Impacts on the surface and underground water resources", in proceedings of the conference Water Resources and Agriculture, Thessaloniki, Greece. (in Greek)

[5] Birol, E., Karousakis, K., Koundouri, Ph. (2006) "Using economic valuation techniques to inform water resources management: A survey and critical appraisal of available techniques and an application", Science of the Total Environment, Vol. 365, pp 105-122.

[6] Genius, M., Manioudaki, M., Mokas, E., Pantagakis, E., Tampakakis, D., and Tsagarakis, K.P., (2005) "Estimation of willingness to pay for wastewater treatment", Water Science and Technology: Water Supply, Vol. 5, No 6, pp 105-113.

[7] Cuesta, T. S., Alvarez, C. J., Cancela, J. J., Miranda, D. and Neira, X. X. (2006) "Wastewater management evaluation by using the opinion survey in Galicia, Spain", Water Resources Management, Vol. 20, pp 817-828.

[8] Loomis J., Kent, P., Strange, L., Fausch, K., Covich A. (2000) "Measuring the total economic value of restoring ecosystem services in an impaired river basin: Results from a contingent valuation survey", Ecological Economics, Vol. 33, pp 103-117.

[9] Karkanakis, V.Z., Matsos, A., Mavromati, P., Ntagianta, G., Genius, M. and Tsagarakis, K.P. (2005) "Economic valuation of the use attributes of Cournas lake in Greece", In IWA International Conference on Water Economics, Statistics, and Finance, 8-10 July, Rethymno, Greece, Vol. II, pp 37-42.

[10] Mallios, Z. and Latinopoulos, P. (2005) "An application of contingent valuation for the economic assessment of irrigation water in a Greek 
agricultural area", In IWA International Conference on Water Economics, Statistics, and Finance, 8-10 July, Rethymno, Greece, Vol. I, pp 310-311.

[11] Tsagarakis, K.P. and Georgantzis, N. (2003) "The role of information on farmers' willingness to use recycled water for irrigation", Water Science and Technology: Water Supply, Vol. 3, No 4, pp 105-113.

[12] Menegaki, A.N. and Hanley, N.D. (2005) "Social acceptability and evaluation of recycled water in Crete", In IWA International Conference on Water Economics, Statistics, and Finance, Rethymno, Greece, Vol. I, pp 559-565.

[13] Abu-Madi, M.O.R. (2004) "Incentive systems for wastewater treatment and reuse in irrigated agriculture in the MENA region: Evidence from Jordan and Tunisia", PhD thesis, Delft University of Technology, Delft, The Netherlands. 